\title{
Acute amiodarone toxicity causing respiratory failure
}

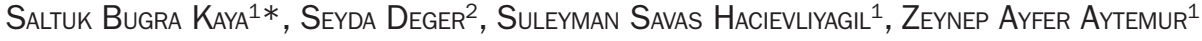 \\ ${ }^{1}$ Department of Chest Diseases, Faculty of Medicine, Inonu University, Malatya, Turkey \\ ${ }^{2}$ Department of Cardiology, Inonu University, Malatya, Turkey
}

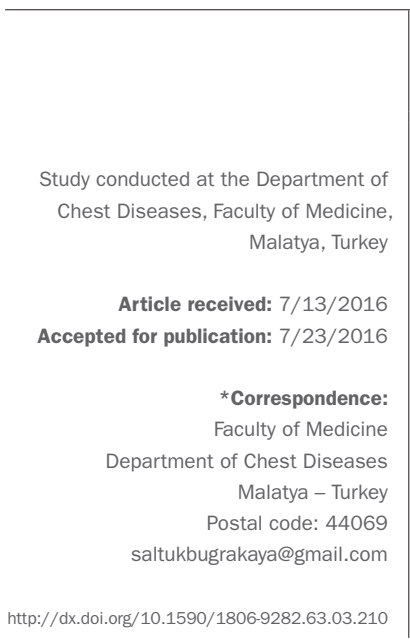

\section{SUMMARY}

A 66-year-old male patient was referred to our clinic with severe pneumonia. Bronchoscopy was performed due to clinical worsening despite antibiotics and diuretic therapy, respiratory failure and radiographic progression. Because bacterial cultures of the bronchoalveolar lavage fluid were negative and after using amiodarone for almost one month, we eliminated amiodarone from his medication regimen due to suspicion of amiodarone toxicity. Accordingly, we also initiated systemic steroid therapy. Chest X-ray done after 72 hours showed a significant resolution of lung consolidations and the patient exhibited significant clinical improvement, with decline of his oxygen requirements.

Keywords: amiodarone, toxicity, respiratory failure.

\section{INTRODUCTION}

At the present time, more than 380 medications are known to cause pulmonary toxicity. ${ }^{1}$ The list of pulmonary toxic drugs is available at the www.pneumotox.com web page. ${ }^{2}$ The most common causal agents are methotrexate, amiodarone, nonsteroidal anti-inflammatory drug (NSAID), nitrofurantoin and angiotensin-converting enzyme inhibitors (ACEI). From 2.5 to $3 \%$ of all interstitial pulmonary diseases are thought to occur due to drugs. Respiratory symptoms occur in approximately $0.5-1.2 \%$ of cases due to drug reactions. ${ }^{3,4}$ The mechanism of amiodarone toxicity is not clear. Pulmonary toxicity develops in $10-15 \%$ of patients using amiodarone. Of these, $10-20 \%$ may develop respiratory failure and death $(A)^{5}(B)^{6}$.

\section{Case report}

A 66-year-old male patient with a history of acute myocardial infarction in the previous month underwent percutaneous coronary intervention and was discharged from the cardiology department with his medical treatment. He presented with dyspnea, cough and sputum for four days, being admitted to a medical center in urban area with a diagnosis of pneumonia and had started antibiotic therapy. Because of progressive deterioration of his clinical state, he was referred to our clinic. Laboratory work up in the emergency department showed white blood cell count (WBC) $13,700 / \mathrm{mL}$, C-reactive protein (CRP) $20.7 \mathrm{mg} / \mathrm{dL}$ and creatinine $1.64 \mathrm{mg} / \mathrm{dL}$. Chest X-ray showed diffuse bilateral nonhomogeneous, irregular interstitial infiltrates (Figure 1). The patient was hospitalized with a pre-diagnosis of pneumonia and pulmonary edema. Piperacillin/tazobactam, ciprofloxacin and furosemide therapy was introduced. He developed worsening of respiratory symptoms and oxygenation. While under the therapy of $10 \mathrm{lt} / \mathrm{dk}$ breathing mask, arterial blood gas showed $\mathrm{pH} 7.47, \mathrm{PO}_{2} 49.9 \mathrm{mmHg}, \mathrm{PCO}_{2} 31.3 \mathrm{mmHg}$, and laboratory tests showed leucocyte 13,200/mL, CRP 27.1 $\mathrm{mg} / \mathrm{dL}$. Chest X-ray showed progression of lesions (Figure 2). Bronchoscopy was planned for the patient. With the failure of bronchoalveolar lavage, bacterial cultures of the lavage fluid were negative. Upon cytologic analyzing of the fluid we saw hemorrhagic, mucoid bronchial epithelial cells, increased inflammatory cells, moreover alveolar macrophages. The specimen was negative for malignancy. The patient's amiodarone was discontinued considering the toxicity of the drug. He was started on steroids with $0.5 / \mathrm{kg}$ dose. The patient's condition promptly improved, with decline of his oxygen requirements. Chest X-ray performed after three days showed regression of the lesions (Figure 3 ). With the improvement of the patient's general condition, he was discharged and referred for polyclinic control (Figure 4).

\section{Discussion}

Amiodarone is a highly effective class III antiarrhythmic agent for the treatment of refractory arrhythmias. The risk for pulmonary and extrapulmonary toxicity is as- 


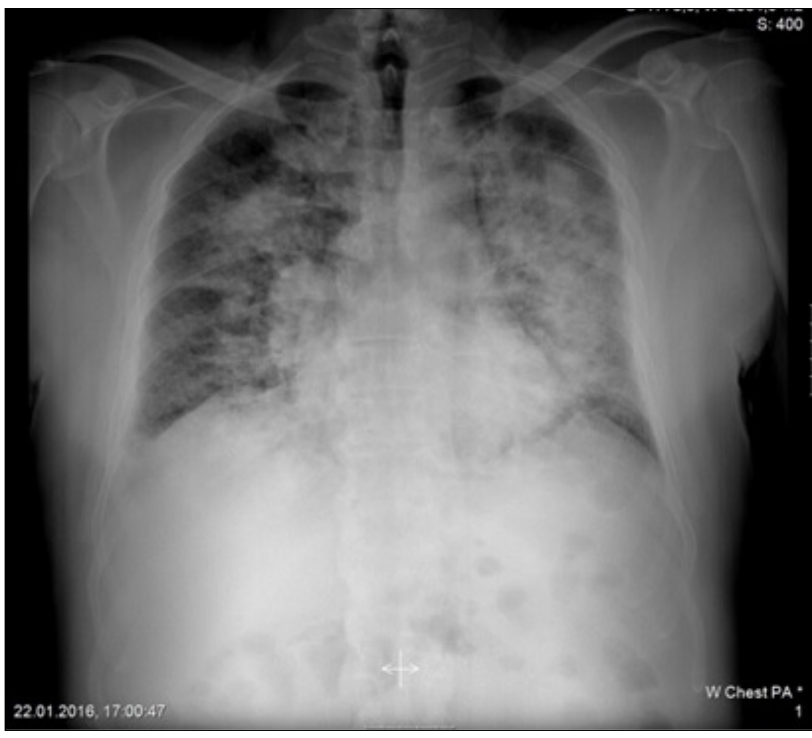

FIGURE 1 Initial chest X-ray showing diffuse bilateral nonhomogeneous, irregular interstitial infiltrates.

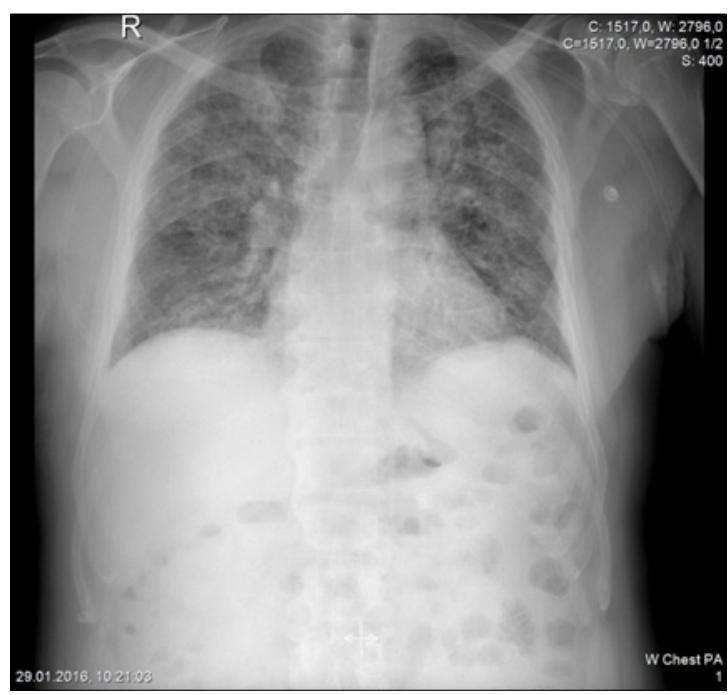

FIGURE 3 Chest X-ray performed after three days showed regression of the lesions.

sociated with a high cumulative dose of amiodarone. Amiodarone has a 30-60 day half-life and high lipid solubility. With potent inhibitory effects on phospholipase, amiodarone leads to accumulation of phospholipids occuring inclusion body in alveolar macrophages and type II pneumocytes in the lungs. The mechanisms of amiodarone pulmonary toxicity are not completely understood. Pulmonary toxicity develops in $10-15 \%$ of patients using amiodarone. Of these, $10-20 \%$ may develop respiratory failure and death. ${ }^{5,6}$ Amiodarone may thus cause direct cellular toxicity through the intracellular

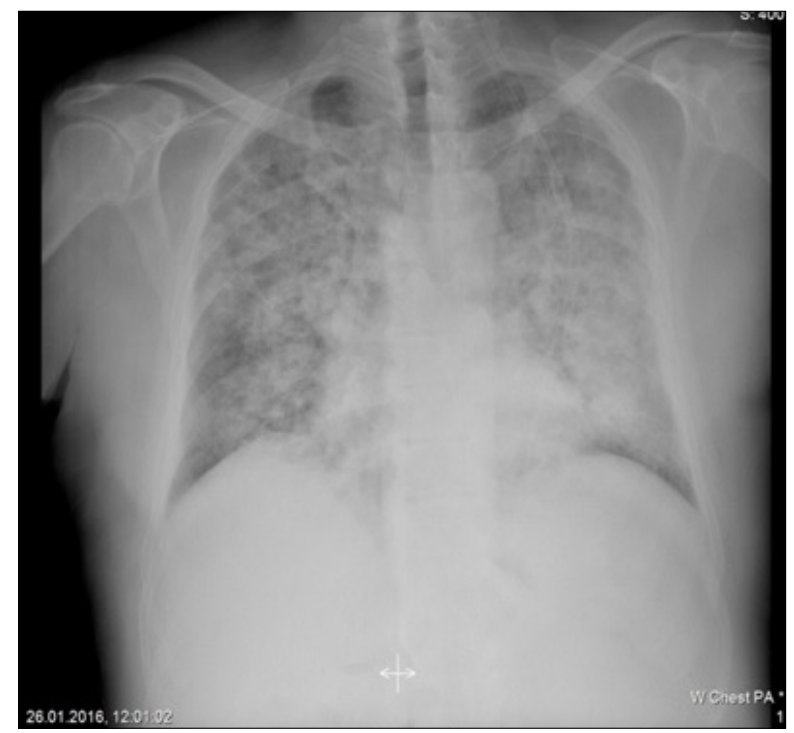

FIGURE 2 Chest X-ray showed progression of lesions.

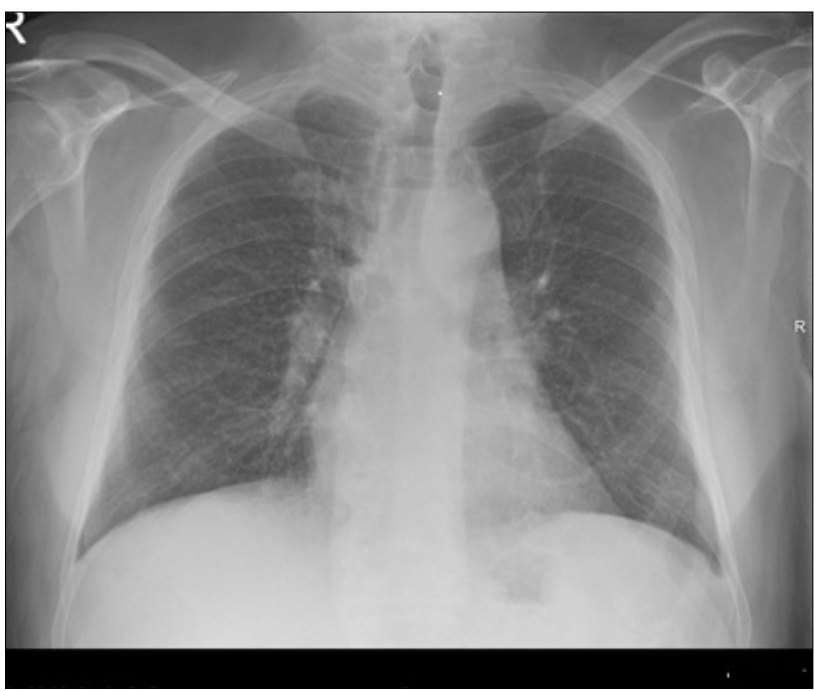

FIGURE 4 Chest X-ray performed after two months showed no infiltrates.

accumulation of phospholipids. ${ }^{7-10}$ Lung toxicity occurs frequently in its chronic form, presenting symptoms such as dyspnea, cough and chest pain and radiographic interstitial infiltrates.

One third of the cases are acute and present with dramatic dyspnea and alveolar infiltrates, which can mimic acute pulmonary infection. ${ }^{11}$ In our case, we thought first of all about pneumonia, but based on negative cultures of the bronchoalveolar lavage (BAL) fluid. After the discontinuation of amiodarone followed by rapid clinical and radiographic recovery, the clinical diagnosis of amiodarone 
due to acute pulmonary toxicity was made. The most frequent symptoms are dyspnea, cough, chest pain and fever, like in our case. Peripheral blood work will usually show leukocytosis, eosinophilia and high value of erythrocyte sedimentation rate (ESR). ${ }^{10,12}$ Radiographic features include characteristically diffuse, bilateral interstitial or alveolar infiltrates. ${ }^{10,13}$ Occasionally, localized, lobar, nodular, masslike or cavitary lesions may be seen. ${ }^{14}$ These lesions appear mostly in the upper lobes and peripheral sites. ${ }^{10,14,15}$ In our patient, the lesions had bilateral diffuse distribution.

The increase of Ga-67 scintigraphy uptake can be seen at the amiodarone induced pulmonary toxicity. Recently, studies reported that Tc-99m-DTPA aerosol scintigraphy is more sensitive than Ga-67 scintigraphy for the detection of amiodarone-induced pulmonary toxicity. ${ }^{16,17}$ We were not able to perform scintigraphic tests because of the patient's clinical state.

Bronchoalveolar lavage may reveal inclusion body in alveolar macrophages and type II pneumocytes of accumulated phospholipids, which are found in all patients exposed to amiodarone. This fact is not indicative of pulmonary toxicity. ${ }^{10,18,19}$ We were not able to perform BAL because of the patient's severe hypoxemia.

Primary treatment is the discontinuation of amiodarone. Due to a long half-life (approximately 45 days), pulmonary toxicity may initially progress despite not taking the drug. Systemic corticosteroids are recommended in a daily dose of 40 to $60 \mathrm{mg}$ with gradually decreased dose for at least 12 months to decrease the symptoms. The prognosis is usually good. One study showed that about $75 \%$ of cases with amiodarone pulmonary toxicity have a favorable outcome after discontinuation of the drug. High mortality rates were reported among patients with acute respiratory distress syndrome. ${ }^{20-22}$ In our case, we discontinued amiodarone first and then began steroid therapy with $40 \mathrm{mg}$ /day doses. After cardiology consultation, due to the late history of acute coronary sendrom, the glucocorticoid therapy was planned for a short time and applied during his hospital stay.

We avoid long term steroid therapy because of significant clinical improvement in a short period of 72 hours. About two months later, in the outpatient examination, chest X-ray was evaluated normal.

Amiodarone is the main drug known to cause pulmonary toxicity. The amiodarone toxicity shows a wide clinical spectrum. This situation, which could mimic pneumonia, may show a mortal course. We presented a case of acute amiodarone pulmonary toxicity that caused respiratory failure.

\section{References}

1. Fagan LN. Foral AP. Malesker MA. Morrow EL. Therapeutic update on druginduced pulmonary disorders. US Pharm. 2011; 36(7):HS3-8.

2. Foucher P. Camus PH. Groupe d'Etudes de la Pathologie Pulmonaire Iatrogene (GEPPI). The drug-induced lung diseases. Pneumotox Online; 2011. Available from: http:www.pneumotox.com.

3. Raissy HH. Harkins M. Marshik PL. Drug-induced pulmonary disease. In: DiPiro JT, Talbert RL, Yee GC, Matzke GR, Wells BG, Posey LM, editors. Pharmacotherapy: a pathophysiologic approach. 7. ed. New York: McgrawHill; 2008. p. 521-34.

4. Costabel U. Radiation and drug induced pneumopathies. Rev Port Pneumol. 2000; 6(2):141-4.

5. Kaushik S, Hussain A, Clarke P, Lazar HL. Acute pulmonary toxicity after low-dose amiodarone therapy. Ann Thorac Surg. 2001; 72(5):1760-1.

6. Massey TE,Leeder RG, Rafeiro E, Brien JF. Mechanisms inthe pathogenesis of amiodarone-induced pulmonary toxicity. Can J Physiol Pharmacol. 1995; 73(12):1675-85.

7. Machado RF, Dweik RA, Demeter SL, Ahmad M. Drug-induced pulmonary disease. In: Crapo JD, Glssroth J, Karlinsky J, Talmadge EK, editors. Pulmonary diseases. New York: Lippincott Williams and Wilkins; 2004. p. 656-77.

8. Camus PH, Foucher P, Bonniaud PH, Ask K. Drug-induced infiltrative lung disease. Eur Respir J Suppl. 2001; 32:93s-100s.

9. Zitnik RJ, Matthay RA. Drug-induced pulmonary diseases. In: Schawartz MI, King TE, editors. Interstitial lung disease. London: BC Decker Inc. Hamilton; 1998. p. 423-49.

10. Camus P, Martin WJ 2nd, Rosenow EC 3rd. Amiodarone pulmonary toxicity. Clin Chest Med. 2004; 25(1):65-75.

11. Vizioli LD, Cho S. Amiodarone-associated hemoptysis. Chest. 1994; 105(1):305-6.

12. Martin WJ 2nd, Rosenow EC 3rd. Amiodarone pulmonary toxicity. Recognition and pathogenesis (Part 1). Chest. 1988; 93(5):1067-75.

13. Martin WJ 2nd, Rosenow EC 3rd. Amiodarone pulmonary toxicity. Recognition and pathogenesis (Part 2). Chest. 1988; 93(6):1242-8.

14. Jarand J, Lee A, Leigh R. Amiodaronoma: an unusual form of amiodaroneinduced pulmonary toxicity. CMAJ. 2007; 176(10):1411-3.

15. Azzam I, Tov N, Elias N, Naschitz JE. Amiodarone toxicity presenting as a pulmonary mass and peripheral neuropathy: the continuing diagnostic challenge. Postgrad Med J. 2006; 82(963):73-5.

16. Dirlik A, Erinc R, Ozcan Z, Atasever A, Bacakoglu F, Nalbantgil S, et al. Technetium-99m-DTPA aerosol scintigraphy in amiodarone induced pulmonary toxicity in comparison with Ga-67 scintigraphy. Ann Nucl Med. 2002; 16(7):477-81.

17. Durmuş-Altun G, Altun A, Aktas RG, Salihoglu YS, Yigitbasi NO. Use of iodine-123 metaiodobenzylguanidine scintigraphy for the detection of amiodarone induced pulmonary toxicity in a rabbit model: A comparative study with technetium-99m diethyltriaminepenta acetic acid radioaerosol scintigraphy. Ann Nucl Med. 2005; 19(3):217-24.

18. Dean PJ, Groshart KD, Porterfield JG, Iansmith DH, Golden EB Jr. Amiodarone associated pulmonary toxicity. A clinical and pathologic study of eleven cases. Am J Clin Pathol .1987; 87(1):7-13

19. Shi JH, Liu HR, Zhu YJ, Xu WB. [Clinicopathologic manifestation of amiodaroneinduced lung injury]. Zhonghua Bing Li Xue Za Zhi. 2006; 35(7):394-7.

20. Ernawati DK, Stafford L, Hughes JD. Amiodarone-induced pulmonary toxicity. Br J Clin Pharmacol. 2008; 66(1):82-7.

21. Coudert B, Bailly F, Lombard JN, Andre F, Camus P. Amiodarone pneumonitis. Bronchoalveolar lavage findings in 15 patients and review of the literature. Chest. 1992; 102(4):1005-12.

22. Myers JL, Kennedy JI, Plumb VJ. Amiodarone lung: pathologic findings in clinically toxic patients. Hum Pathol. 1987; 18(4):349-54. 